\title{
A PRÁTICA DO PORTFÓLIO E O USO PLATAFORMA MOODLE NA SALA DE AULA DE GEOGRAFIA: PERSPECTIVAS PARA UMA GEOGRAFIA EDUCATIVA
}

\author{
E. C. Silva ${ }^{1}$ \\ ${ }^{1}$ Campus Natal Central - Instituto Federal do Rio Grande do Norte \\ E-mail: erineide.silva@ifrn.edu.br
}

Artigo submetido em outubro/2013 e aceito em outubro/2013

\section{RESUMO}

Este trabalho relata experiência vivenciada nas aulas de Geografia, em cursos técnicos de Nível Médio Integrado, do Instituto de Educação Ciência e Tecnologia do Rio Grande do Norte - IFRN, Campus Natal Central, com uso da Plataforma Moodle e o gênero portfólio. A opção por essa metodologia veio ao observar que grande parte dos nossos alunos chega ao Ensino Médio com pouca familiaridade com o hábito do registro, escrita e exercício de reflexão. Para socialização das produções foi utilizada a plataforma Moodle: http://ead.ifrn.edu.br/moodle/, recurso utilizado pela
Instituição nos cursos a distância. Constamos que, quando motivados, os alunos nos dão as respostas significativas e que é possível superar a ideia inicial que muitos ainda chegam ao Ensino Médio, em relação ao estudar Geografia: conteúdos decorativos com aulas centradas no professor e deve se estudar para fazer provas e atividades para obtenção de uma nota no final do bimestre. Houve avanços significativos quanto ao exercício da escrita, criticidade, criatividade. Além do despertar para a relevância da plataforma Moodle no processo ensino-aprendizagem e inclusão digital.

PALAVRAS-CHAVE: Geografia, Aprendizagem significativa, Curta-metragem, Ensino Fundamental.

\section{THE PRACTICE OF PORTFOLIO AND USE MOODLE PLATFORM IN THE CLASSROOM OF GEOGRAPHY: PROSPECTS FOR AN EDUCATIONAL GEOGRAPHY}

\begin{abstract}
This paper reports the experiences gathered on teaching Geography at Vocational Education Courses bound to High School, in the Institute of Education, Science and Technology of Rio Grande do Norte - IFRN, in the Campus Natal-Central, using the Moodle platform and the portfolio genre. We have chosen this methodology once noticing that most of our students start in High School with poor familiarity on the habit of recording, writing and on the exercise of thought. In order to publish the production, we used the Moodle platform:
\end{abstract}

http://ead.ifrn.edu.br/moodle/, the device used by the Institution in distance learning courses. We found that, when motivated, the students give us meaningful answers and that it is possible to overcome the initial idea that many still come to school only to memorize the contents and make a good test. There have been significant advances regarding the exercise of writing, criticality and creativity, besides the arousing to the relevance of the Moodle platform in the teachinglearning process and digital inclusion.

KEYWORDS: Geography, Meaningful Learning, Short film, Elementary School. 


\title{
A PRÁTICA DO PORTFÓLIO E O USO PLATAFORMA MOODLE NA SALA DE AULA DE GEOGRAFIA: PERSPECTIVAS PARA UMA GEOGRAFIA EDUCATIVA
}

\section{O PORTFÓLIO NAS AULAS DE GEOGRAFIA: POR QUÊ? PARA QUÊ?}

\begin{abstract}
Informação, conhecimento, sabedoria. Essas três palavras são usadas apressadamente como se fossem sinônimas, como se significassem a mesma coisa. Mas é preciso, por um lado, distingui-las; por outro, compreender que da metamorfose da primeira na segunda e da segunda na terceira depende, em grande parte, saber bem para enfrentar e conviver com os enormes problemas e desafios colocados hoje nos níveis locais e globais.
\end{abstract}

(Conceição Almeida)

Espera-se do ensino de Geografia, o desenvolvimento do educando, de forma que este possa compreender a dinâmica socioespacial do mundo atual, tendo com ponto de partida sua realidade, na perspectiva de nela atuar criticamente, objetivando sua transformação. Por essa razão, credita-se a esse fazer a superação aulas com objetivo de apenas partilhar informação, transmiti-las, para chegarmos a "uma geografia educadora", como nos mostra Rego (2007, p. 9).

Essa prática é envolvida pela complexidade que envolve o processo educativo, tornandose um grande desafio para nós educadores: promover um fazer significativo que contemple uma formação integral do educando. Nesse contexto, a Geografia na sala de aula deve oportunizar ao aluno a compreensão das relações socioespaciais em suas mais diversas contradições que se estabelecem cotidianamente em seu lugar-mundo, de forma que proporcione um entendimento do espaço em sua totalidade.

Os Parâmetros Curriculares Nacional (PCNs) do Ensino Médio entendem a necessidade dessa prática e orientam que o ensino de Geografia deve possibilitar ao educando localizar, compreender e atuar no mundo complexo, problematizar a realidade, formular proposições, reconhecer as dinâmicas existentes no espaço geográfico, pensar e atuar criticamente em sua realidade, tendo em vista sua transformação. (BRASIL, PCNs Ensino Médio, 1999).

O projeto pedagógico do curso Técnico de Nível Médio, do Instituto de Educação Ciência e Tecnologia do Rio Grande do Norte - IFRN fundamenta-se nessa ótica, ao entender que sua função é promover educação científico-tecnológico-humanística, visando à formação do profissional-cidadão crítico-reflexivo, competente técnica e eticamente e comprometido com as transformações sociais, políticas e culturais. 
O anseio é que tenhamos cidadãos conscientes e participativos com vistas à compreensão de sua realidade, buscando significados para os fenômenos geográficos existentes, como também alimentar o sonho de uma realidade construída, com sentido para a vida da humanidade. Isso significa a necessita de despertar e unir-se, a fim de buscar um mundo mais produtivo e, ao mesmo tempo, mais justo e ambientalmente equilibrado. Um mundo menos excludente, em que toda sociedade humana, e não apenas um pequeno grupo privilegiado, possa usufruir das benesses da modernidade.

A partir dessa percepção de ensino de Geografia, de uma Geografia educadora que desenvolvemos nossa prática educativa, na perspectiva de contribuir para que a instituição possa cumprir com a sua função social: além de oferecer um conhecimento sistematizado, saberes e habilidades, educar para vida, formar cidadãos participativos, críticos. Um grande desafio! Mas, nós educadores temos que enfrentá-lo cotidianamente e não nos sentirmos impotentes diante das amarras do sistema de ensino, cujo paradigma dominante ainda persiste recheado com um fazer linear, cartesiano e "bancário" (FREIRE, 1989).

Como nos mostra Rego (2007), os obstáculos podem ser impedimentos, ou desafios. Mas, a finalidade de sonhar, por pouco que seja, permite-nos escapar das armadilhas de fazer tudo, como se tudo devesse ser feito como reflexo do já dado. "É finalidade do sonho é sondar o que se agita em busca de formas possíveis nos desvãos do cotidiano [...]" (REGO, 2007, P.11).

A ideia de sonho apresentada acima por Rego (2007) foi amplamente defendida pelo ilustre educador Paulo Freire. Este defendeu a utopia enquanto obtenção das conquistas, como um sonho a ser buscado e trilhado para se atingir algo. Penso que esse é sonho daqueles que investem em uma Geografia educadora, cuja ação é alimentada pelo sentimento de inquietude em relação à realidade vivenciada e, possivelmente, uma mesma inquietude pela busca de sua transformação.

Essas inquietudes presentes em nosso cotidiano têm nos instigados em tentar proporcionar ao nosso aluno, vivências significativas que possam auxiliar em seu processo formativo. Nesse momento, gostaríamos de socializar a experiência desenvolvida, a partir do uso do portfólio nas aulas de Geografia, no curso Técnico em Informática, turma dos 10 Ano do Ensino Médio: cursos Geologia, Controle Ambiental, Edificações e Informática, turno matutino, no Instituto de Educação Ciência e Tecnologia do Rio Grande do Norte - IFRN, Campus CentralNatal, ministradas durante o ano letivo de 2010.

Acreditamos que a elaboração do portfólio se constitui em um processo de dimensão abrangente: atitudinal, conceitual e procedimental, bem como por observar que grande parte dos nossos alunos chega ao Ensino Médio com pouca familiaridade com o hábito do registro, escrita e exercício de reflexão. Como espaço para socialização, foi utilizado a plataforma Moodle: http://ead.ifrn.edu.br/moodle/, recurso utilizado pela Instituição nos cursos a distância.

Para elaboração deste, orientamos que não havia um roteiro fechado a ser seguido, pois se tratava de um trabalho pessoal e eles tinham a liberdade de escolher o caminho que desejavam trilhar. Apenas recomendamos que representassem significativamente o conteúdo 
trabalhado, justificassem as escolhas, procurassem organizar em textos reflexivos e desenvolvessem espírito de criticidade, auto avaliação, autonomia de pensamento.

Essa prática perpassa pela superação do entendimento de avaliação como um procedimento terminal, punitivo, classificatório, seletivo e excludente, comumente ainda aplicados no decorrer ou final de bimestres, na maioria das instituições de ensino. Da mesma forma, significa que aprender deve ser uma busca contínua, cujo caminho a ser percorrido nem sempre é de fácil acesso, por isso deve ser trilhado com objetivos sólidos, talvez até de forma lenta, mas com a convicção de que devemos persegui-lo e que a satisfação virá com a concretização da prática, como essa ora partilhada e, consequentemente, com a efetivação saber construído, efetivado.

\title{
2. PORTFÓLIO: INSTRUMENTO DE FORMAÇÃO REFLEXIVA E AVALIAÇÃO
}

Adotamos o portfólio em nosso fazer, por compreender que este se constitui em um processo que promove acompanhamento, mediação, diálogo e intervenção mútua entre o ensino e as aprendizagens, podendo tornar-se importante ferramenta no ensino de Geografia ao favorecer a capacidade de registro e reflexões de vivências. No processo de elaboração, o aluno reflete, justifica, contextualiza e explica a realidade vivenciada, a partir de temas/conteúdos o ajudam dialogar com seu lugar-mundo.

Mas, o que é e como fazer um portfólio? Bernardes \& Miranda (2003) chamam atenção para o fato de que um portfólio não é um mero repositório de trabalhos "organizados" em uma pasta de arquivo ou em uma caixa. Nesse sentido, enquanto instrumento de avaliação, trata-se de um conjunto de elementos, acompanhados de indicações e de comentários estruturados, reflexões, auto avaliação, escolhidos pelo aluno e/ou pelo professor, com a finalidade de demonstrar o desenvolvimento de sua aprendizagem e/ou dificuldades encontradas no percurso.

HERNANDEZ (1998) entende o portfólio como:

\begin{abstract}
um continente de diferentes classes de documentos (notas pessoais, experiências de aula, trabalhos pontuais controles de aprendizagem, conexões com outros temas fora da Escola, representações visuais, etc.) que proporciona evidências do conhecimento que foi sendo construído, das estratégias utilizadas para aprender e da disposição de quem o elabora em continuar aprendendo (HERNANDEZ 1998, p. 100).
\end{abstract}

Por essa razão, acreditamos que o portfólio, além de se constituir em procedimento de ensino-aprendizagem, deve ser entendido como um processo de avaliação contínua. Através deste, é possível superar a concepção de avaliação centrada em provas; em um trabalho acabado, com conceitos prontos e, às vezes, copiados sem reflexão.

No ensino de Geografia, sua prática deve contribuir para que o aluno compreenda as relações socioespaciais em suas mais diversas contradições que se estabelecem cotidianamente em seu lugar-mundo, com intuito de favorecer a compreensão do espaço em sua totalidade. A 
ideia é que se busque "uma postura mais investigativa. Que reproduza menos generalidades que tanto povoam a Geografia" (KAECHER, 2006).

O objetivo é construir o diálogo lugar-mundo, ampliar as possibilidades de aquisição de um conhecimento estruturado, mediado pela escola com o propósito de conduzir a construção da autonomia necessária ao exercício da cidadania, o reconhecimento da dinâmica existente no espaço geográfico.

Tara-se do momento de oportunizar ao aluno de Geografia a ampliação do desenvolvimento da criticidade e uma formação integral. Estimula-se o desenvolvimento de sua capacidade de identificar as contradições que se manifestam espacialmente decorrentes dos processos produtivos e de consumo, bem como a compreensão do papel das sociedades na produção do espaço, do território, da paisagem e do lugar.

Partilhamos do pensamento de Freire (2002), quando nos mostra que o conhecimento crítico é obtido de uma forma autenticamente reflexiva e implica em um ato constante de desvelar a realidade, posicionando-se nela. A construção do saber erigido sob essa ótica possibilita a superação de uma consciência ingênua, alicerçada a partir de uma leitura aparente da realidade, para se alcançar a consciência crítica ${ }^{1}$ e assim, fazer a leitura do mundo.

$\mathrm{Na}$ opinião desse educador, a leitura de mundo é imprescindível para despertar a necessidade de transformação da realidade. É essa leitura que o ensino de Geografia deve proporcionar ao aluno: um despertar para a realidade via ações pedagógicas que favoreçam a formação do educando enquanto um cidadão crítico.

\section{O PROCESSO DE ELABORAÇÕES DOS PORTFÓLIOS}

Essa proposta de trabalho obteve boa receptividade pela turma. Mesmo diante de muitos questionamentos, insegurança (como fazê-los? O que estamos fazendo está certo?). A ideia do certo e do errado esteve muito presente nos primeiros momentos. Mas, logo foi superado à medida que socializávamos alguns textos e contatávamos diferentes formas de apresentar os temas abordados. Cada um registrava com seu olhar, sem perder de vista a essência do tema.

Pela qualidade dos trabalhos obtidos, observamos que essa vivência foi uma oportunidade ímpar para superarmos a ideia, às vezes, ainda persistente de que na sala de aula só o professor ensina e alunos aprendem apenas com o professor. Essa aprendizagem surgia a partir da socialização dos portfólios, através de e-mails, trabalhos impressos, postagem dos trabalhos na Plataforma Moodle e a leitura de alguns textos em sala de aula.

Vale registrar que começamos a vivenciar essa prática a partir do ano de 2009, e demos continuidade com essa proposta de trabalho, ampliando o universo para quatro (4) turmas de 1 o ano (Ensino Médio) em 2010, momento em que passamos a contar com mais uma ferramenta que a Plataforma Moodle, utilizada nos cursos à distância, oferecidos no IFRN. Em 2011 demos

\footnotetext{
${ }^{1}$ Capacidade de superação da aparência, o que possibilita chegar à essência da realidade.
} 
continuidade, iniciado a experiência com alunos do $2^{\circ}$ Ano, Cursos de Técnicos (Regular) de Controle Ambiental, Mecânica, Mineração e Eletrotécnica, turno vespertino.

Entendemos que a partir dessa prática, estamos contribuindo para familiarização de novo paradigma ensino e de avaliação, bem como oportunizamos a perspectiva de uma formação integral do educando, ao proporcionar o desenvolvimento do espírito crítico. Consequentemente, temos a ampliação da capacidade de identificar as contradições que se manifestam espacialmente decorrentes dos processos produtivos e de consumo, além da compreensão do papel das sociedades na produção do espaço, do território, da paisagem e do lugar.

Sob essa ótica, o aluno tem a oportunidade de estabelecer conexões entre os fenômenos geográficos, analisa-o e explica via argumentos construídos das reflexões promovidas no decorrer do processo formativo.

A ideia é de que a construção do saber a partir dessa vivência possa contribuir para a superação de uma consciência ingênua, alicerçada a partir de uma leitura aparente da realidade, para se alcançar a consciência crítica, e assim fazer uma leitura do mundo (FREIRE, 2000).

Essa leitura de mundo é imprescindível na prática de uma geografia educadora, pois é através desta que despertamos para exercício da criticidade, da cidadania, em que o sujeito passa a questionar e analisar as coisas não por que alguém exige que ele o faça, mas porque no fundo, possui o desejo de compreender e buscar respostas às interrogações nascidas do contato com o meio em que vive, conforme registro do aluno:

\footnotetext{
Nós podemos concluir que a geografia, sendo um forte fundamento para o conhecimento humano sobre si e o próprio mundo em que vive, também possui fundamentos, bases e alicerces que necessários no princípio do estudo desta diferente ciência. Conceitos primordiais sempre são mencionados e são de corriqueiro uso dentro do meio geográfico e por muitas vezes são passados sem a importância merecida a eles. (M O. S, CURSO INFORMÁTICA 2009).
}

A colocação desse aluno nos leva a partilhar da inquietação de Kaecher (2006) quando nos mostra que o ensino de Geografia continua desacreditado.

\footnotetext{
Os alunos, no geral, não têm mais paciência para nos ouvir. Devemos não apenas nos renovar, mas ir além, romper a visão cristalizada e monótona da Geografia como ciência que descreve a natureza e/ou dá informações gerais sobre uma série de assuntos e lugares. Devemos fazer como que o aluno perceba qual a importância do espaço na constituição de sua individualidade e da(s) sociedade(s) de que ela faz parte (escola, família, cidade, país, etc.) (KAECHER, 2006).
}

Assim como Kaecher, acreditamos na importância e imensas potencialidades do ensino de Geografia, para contribuir com uma leitura holística e dinâmica do mundo. Nos recortes apresentamos no decorrer da sequência desse trabalho, de pronunciamento dos alunos registrados nos portfólios demonstram essa capacidade de leitura e reflexão do mundo. 
A escolha dos recortes ${ }^{2}$ apresentados deu-se de forma aleatória, a partir de trabalhos que foram entregues em meio digital e ficamos com cópia. Os demais, impressos ou manual foram devolvidos no final dos bimestres.

\begin{abstract}
Esse trabalho foi muito importante, uma vez que me fez exercer meu papel de estudante, cidadão e agente transformador, atuando na minha própria residência. Promovendo uma mudança agradável não só no quesito ambiental, mas inclusive no econômico. Fazendo-me entender que nos podemos começar a mudar o mundo em que vivemos através de simples transformações em nossa casa, querendo aquela barreira entre os diversos problemas ambientais e sociais que estudamos na escola e a atuação para o combate destes (Y. N, CURSO INFORMÁTICA, 2010).
\end{abstract}

... O Moodle proporcionou um momento de reflexão sobre os assuntos tratados em aula, fazendo assim com que eu realmente entendesse para expor aqui minhas ideias sobre o que aprendi, a partir da leitura tanto no livro quanto em sites na internet. Como sempre, a professora nos mostrava uma visão crítica, relacionando a preservação do meio ambiente com o conteúdo dado em sala... (A. V. F. F. CURSO GEOLOGIA, 2010).

Essas colocações nos fazem acreditar que é possível abraçar a geografia educadora. Embora seja desafiador, a satisfação de nos arriscarmos na busca de um fazer mais significativo, de tentar mostrar que é possível trabalhar o conteúdo, respeitar um programa proposto, mesmo que elaborado de forma fragmentada, ainda persistente em nosso fazer. A perspectiva foi superar sua linearidade e trabalhar de forma significativa e contextualizada. Esse fazer, mesmo que desafiador, tem-nos reforçado, como mostra Castrogiovanni (2007) que é imprescindível ao educador à audácia e predisposição às mudanças, por mais difícil e utópica que possam parecer no primeiro momento.

Para os alunos, como estavam diante de algo novo, surgia a insegurança acompanhada de vários questionamentos. Como sistematizar o conteúdo trabalhado? Qual gênero textual escolher, o que pode ter em meu texto? Por que não elaborar um roteiro para todos seguirem? Essas dúvidas, dentre outras acompanharam quase todo o primeiro bimestre. Queriam respostas se estavam certos ou errados. Mas à medida que íamos socializando algumas produções no decorrer das aulas, aos poucos, estes ganharam autoconfiança e autonomia para continuar produzindo seus textos, com menos insegurança.

\title{
4. ALGUMAS CONSIDERAÇÕES
}

Diante desse trabalho ficou evidente que, quando motivados, os alunos nos dão as respostas significativas e que é possível superar a ideia inicial que muitos chegam ao Ensino Médio, em relação ao estudar Geografia: conteúdos decorativos com aulas centradas no professor e deve se estudar para fazer provas e atividade para obtenção de uma nota no final do bimestre. E mais o seu estudo não é muito interessante e que o seu conhecimento virá apenas dos livros didáticos, ou do discurso do professor e até mesmo da mídia, através da divulgação de informações de acontecimentos geográficos. Por exemplo, certa vez ouvi de um aluno,

\footnotetext{
${ }^{2}$ Esses recortes estão citados tal qual o registro do aluno. Pensamos em resumir, mas desistimos, pois poderíamos correr o risco de deixar prevalecer o nosso olhar, que talvez modificasse o do aluno.
} 
comentando com um colega, certa estranheza, mas de forma satisfatória, que estudou Geografia em todo o Ensino Fundamental, mas só no decorrer das aulas do 10 ano, 2010, que ele tinha compreendido o porquê e para que estudar Geografia.

O propósito foi mostrar ao aluno que ele é produtor de conhecimentos e que deve ser visto como sujeito ativo e ator/autor de sua formação. Foi um momento ímpar para o aluno descobrir-se enquanto agente propositivo na sua vida escolar e na sociedade em vive e para nós, professores que vivenciamos as respostas às situações provocadas. Por outro lado, vale registrar que não foi uma tarefa fácil, pois logo no início havia reclamações de alguns que achavam ser uma tarefa muito difícil, pois muitos nunca tinham ouvido se quer a palavra portfólio e muito menos Plataforma Moodle. Mas esse desafio foi superado no processo formativo.

A maioria dos alunos apresentou trabalhos excelentes e avançou significativamente na questão da escrita, da reflexão e na capacidade de fazer relações. Os fenômenos geográficos já não eram mais vistos descontextualizados. Passaram a descobrir o significado de estudar geografia, a sua importância no cotidiano da sociedade, conforme mostra a fala da aluna:

Olá, bem vindo (a) ao meu portfólio do 4 o bimestre! Primeiramente quero agradecer as professoras pela atenção, cuidado e dedicação que elas tiveram conosco durante todo o ano, embora eu só tenha passado a metade dele por aqui, e também parabenizá-las pelo ótimo trabalho exercido. Sinceramente eu não gostava de Geografia, mas ao longo do ano aprendi que temos que parar e ouvir o que o outro tem a dizer, e com isso talvez algo que você não goste venha a ser seu passatempo preferido (M. I. S. S., CURSO INFORMÁTICA, 2010).

O mais importante foram avanços quanto ao exercício da criticidade. Vale registrar que através da criticidade, o sujeito passa a questionar e analisar as coisas não porque alguém exige que ele o faça, mas porque no fundo, ele possui o desejo de compreender e buscar respostas às interrogações nascidas do contato com as pessoas, com o meio em que vive (local-global). Entendemos que é aí que a geografia educadora cumpre o seu papel: a formação da cidadania. O ensino de Geografia na contemporaneidade deve reconhecer que formação reflexiva é imprescindível e que "o objetivo da educação é ajudar a tornar as pessoas mais livres, menos dependentes do poder econômico, político e social. E a profissão de ensinar tem essa obrigação intrínseca". (IMBERNÓN, 2005, p.27).

\section{CONSIDERAÇÕES FINAIS}

Ressaltamos ainda a relevância da plataforma Moodle, por dar continuidade da discussão via fóruns na Plataforma; desenvolvimento da escrita, reflexão criticidade; Redução do uso do papel e acesso a uma maior quantidade de atividades, que impressa não seria possível e, portanto, ampliação da consciência ambiental; inclusão digital, embora grande parte dos alunos não tenham internet em casa, o que despertou logo no 1 ․ Ano a importância do uso dos laboratórios de informática do Instituto. 


\section{REFERÊNCIAS}

BERNARDES, Carla; MIRANDA, Filipa Bizarro. Portefólio: uma escola de competências. Porto, Portugal: Porto Editora, 2003.

CASTROGIOVANNI, Antônio Carlos. Para entender a necessidade de práticas prazerosas no ensino e geografia na pós-modernidade. In: REGO, Nelson; CASTROGIOVANNI, Antônio Carlos; KAERCHER, Nestor André (Orgs.). Geografia: prática pedagógicas par ao ensino médio. Porto Alegre: Artmed, 2007.

BRASIL, Orientações Curriculares para o Ensino Médio, 2008. Ciências Humanas e suas tecnologias. Brasília: MEC, Secretaria de Educação Básica, 2008.

BRASIL, Ciências Humanas e suas tecnologias. Parte IV, Conhecimentos de Geografia. In: Parâmetros Curriculares Nacionais: Ensino Médio. Brasília: MEC, Secretaria de Educação Básica, 1999.

FREIRE, Paulo. Pedagogia do oprimido. 25. ed. Rio de Janeiro: Paz e terra, 1998.

Pedagogia da autonomia: saberes necessários à prática educativa. 15. ed. São Paulo: Paz e Terra, 2000.

GADOTTI, Moacir. Boniteza de um sonho: ensinar-e-aprender com sentido. São Paulo: Editora e Livraria Instituto Paulo Freire, 2008.

HERNANDEZ, Fernando. A avaliação como parte do processo dos projetos de trabalho. In: Transgressão e mudança na educação: os projetos de trabalho. Trad. Jussara Haubert Rodrigues. Porto Alegre: Artmed, 1998.

IFRN. Projeto pedagógico do curso Técnico de Nível Médio em Informática na forma integrada, na modalidade presencial. Natal-RN, 2009.

IMBERNÓN, Francisco. Formação docente e profissional: formar-se para a mudança e a incerteza. 5. ed. São Paulo: Cortez, 2005.

KAERCHER, Nestor André. O gato comeu a Geografia Crítica? Alguns obstáculos a superar no ensino-aprendizagem de Geografia. In: PONTUSCHKA, Nídia Nacib; OLIVEIRA, Ariovaldo Umbelino de. Geografia em perspectiva. 3. Ed. São Paulo: Contexto, 2006.

REGO, Nelson. Geografia educadora, isso serve para. In: REGO, Nelson; CASTROGIOVANNI, Antônio Carlos; KAERCHER, Nestor André (Orgs.). Geografia: práticas pedagógicas para o Ensino Médio. Porto Alegre: Artmed, 2007. 